\title{
A CONTRIBUIÇÃO DOS INSTRUMENTOS AVALIATIVOS PARA A AUTONOMIA NA EDUCAÇÃO A DISTÂNCIA
}

\author{
THE CONTRIBUTION OF EVALUATION INSTRUMENTS TO AUTONOMY IN \\ DISTANCE EDUCATION
}

\section{LA CONTRIBUICIÓN DE LOS INSTRUMENTOS EVALUADORES A LA AUTONOMÍA EN LA EDUCACIÓN A DISTANCIA}

\author{
Leandro de Oliveira Silva ${ }^{1}$ \\ Universidade Estadual Norte Fluminense - UENF \\ David Almeida dos Santos 2 \\ Universidade Estadual Norte Fluminense - UENF \\ Hellen Candida Alves ${ }^{3}$ \\ Universidade Estadual Norte Fluminense - UENF
}

\begin{abstract}
Resumo
Este trabalho tem como objetivo analisar os principais instrumentos avaliativos empregados na Educação a Distância (EaD), investigando como interferem na prática pedagógica e no desenvolvimento da autonomia discente. Para isso, foi aplicado um questionário com perguntas destinadas a professores de escolas estaduais de uma cidade do Estado do Rio de Janeiro, que tenham participado de pelo menos um curso na modalidade a distância nos últimos cinco anos. Por
\end{abstract}

\footnotetext{
${ }^{1}$ Possui graduação em Ciências Biológicas pela Universidade Federal do Rio de Janeiro (UFRJ/CEDERJ, 2009); graduação em Pedagogia pela Universidade Federal do Estado do Rio de Janeiro (UNIRIO/CEDERJ, 2015); Especialização em Educação Ambiental e Sustentabilidade pela Universidade Cândido Mendes (UCAM/PROMINAS, 2012); Especialização em Gestão Escolar Integrada pela Universidade Cândido Mendes (UCAM/PROMINAS, 2015); Especialização em Planejamento, Implementação e Gestão da Educação a Distância pela Universidade Federal Fluminense (UFF, 2015) e Mestrado em Biociências e Biotecnologia pela Universidade Estadual do Norte Fluminense Darcy Ribeiro (UENF), trabalhando no Laboratório de Química e Função de Proteínas e Peptídeos. ORCID: https://orcid.org/0000-0003-1651-7760. Lattes: http://lattes.cnpq.br/7160040676613371. E-mail: oliveiradasilvaleo@gmail.com.

${ }^{2}$ Graduado em Ciências Biológicas e Cientista de Alimentos pelo Instituto Federal Fluminense Campus Bom Jesus do Itabapoana - RJ (2013 - 2016). ORCID: https://orcid.org/0000-0003-4007-0786. Lattes: http://lattes.cnpq.br/7305489881434622. E-mail: davidpqdt8@gmail.com.

3 Técnica em Química pelo Instituto Federal Fluminense (IFF), campus Bom Jesus e atualmente Graduanda de Licenciatura em Ciências Biológicas na modalidade EAD pela Universidade Estadual do Norte Fluminense Darcy Ribeiro (UENF). ORCID: https://orcid.org/0000-0002-4842-254X. Lattes: http://lattes.cnpq.br/3424826917421458. E-mail: hellentquimicaiff@gmail.com.
} 
meio da análise dos resultados foi possível observar que existe consenso quanto à importância da avaliação formativa para o desenvolvimento do educando, ainda que grande parte dos professores também reconheça a avaliação somativa (aquela que considera apenas um resultado final como válido) como importante. Observou-se, também, que a maioria dos professores afirma avaliar seus alunos com instrumentos diferentes daqueles utilizados nos cursos EaD considerados. Conclui-se que a autoavaliação, enquanto instrumento de fundamental importância para o desenvolvimento da autonomia discente, é subutilizada na EaD. Faz-se necessário pensar sobre o papel da autoavaliação enquanto promotora do desenvolvimento do aluno da EaD.

Palavras-chave: Instrumentos de Avaliação; Autoavaliação; Professores.

\section{Abstract}

This work aims to analyze the main evaluation instruments used in Distance Education (DE), investigating how they interfere in pedagogical practice and in the development of student autonomy. For this, a questionnaire was applied with questions for teachers of state schools in a city in the state of Rio de Janeiro who have participated in at least one course in the distance modality in the last five years. Through the analysis of the results it was possible to observe that there is a consensus as to the importance of formative evaluation for the development of the student, although most teachers also recognize the summative evaluation (the one that considers only a final result as valid) as important. It was also observed that most teachers claim to evaluate their students with different instruments than those used in the DE courses considered. It was concluded that self-evaluation as an instrument of fundamental importance for the development of student autonomy is underused in $D E$. It is necessary to think about the role of self-evaluation as a promoter of the development of DE students.

Keywords: Evaluation Tools; Self-Evaluation; Teachers.

\section{Resumen}

Este trabajo tiene como objetivo analizar los principales instrumentos de evaluación utilizados en la Educación a Distancia (EaD), investigando cómo interfieren en la práctica pedagógica y en el desarrollo de la autonomía del alumno. Para ello, se aplicó un cuestionario con preguntas para los maestros de escuelas públicas de una ciudad del Estado de Rio de Janeiro, que al menos hayan participado en un curso de educación a distancia en los últimos cinco años. A través del análisis de los resultados se pudo observar que existe un consenso en cuanto a la importancia de la evaluación formativa para el desarrollo del alumno, aunque la mayoría de los maestros también reconocen como importante la evaluación sumativa (aquella que considera solo un resultado final como válido). También se observó que la mayoría de los maestros afirman evaluar a sus alumnos con instrumentos distintos a los utilizados en los cursos EaD considerados. Se concluye que la autoevaluación, como instrumento de fundamental importancia para el desarrollo de la autonomía del alumno, es infrautilizada en EaD. Es necesario pensar en el papel de la autoevaluación como promotora del desarrollo del estudiante de EaD.

Palabras clave: Instrumentos de Evaluación; Autoevaluación; Maestros.

\section{INTRODUÇÃO}

Avaliar é uma atividade constante na prática pedagógica, seja ela presencial ou a distância. Sem avaliação é difícil acompanhar, de forma satisfatória, o processo de ensino- 
aprendizagem, uma vez que não basta apresentar conteúdos aos educandos, mas é preciso monitorar os acertos e erros intrínsecos ao ato de aprender, buscando meios de corrigir os desvios da própria prática pedagógica. A forma como se avalia está intimamente associada aos instrumentos empregados e à concepção de ensino orientadora do trabalho do avaliador. Desta forma, a avaliação pode assumir três principais funções: diagnóstica, mediadora (ou formativa) e somativa (ou quantitativa), a depender do momento em que é aplicada e do uso que é feito dos resultados obtidos.

$\mathrm{O}$ ato de avaliar, longe de ser neutro, é imbuído de significados e valores intimamente associados àquele que pratica a avaliação - o que inclui desde a escolha dos instrumentos a serem utilizados até o que será feito dos resultados obtidos. Na Educação a Distância (EaD), em especial, a prática avaliativa não pode contar com a presença física do avaliador e do avaliado, utilizando-se, majoritariamente, das Tecnologias da Informação e Comunicação (TICs) como suporte para que a avaliação aconteça. Este contexto de separação espacial e temporal cria novas necessidades e desafios ao ato de avaliar, não podendo limitar-se a coletar informações sobre o quanto o sujeito apreendeu do conteúdo trabalhado, mas criar condições para que a avaliação cumpra seu papel de auxiliar professor e aluno na construção de saberes.

Implementar uma avaliação que possibilite ao cursista pensar sobre seu posicionamento em relação à sua própria formação, atitudes, valores e crescimento pessoal é algo necessário frente às especificidades dos cursos $\mathrm{EaD}$, que exigem uma maior autonomia do educando. Neste contexto, a autoavaliação mostra-se como um instrumento extremamente importante de ser utilizado para o desenvolvimento do aluno da EaD, especialmente quando constatamos que a mesma cria um paradoxo: ao mesmo tempo em que é valorizada pelos cursistas, é subutilizada ou simplesmente não empregada nos cursos.

A autoavaliação, enquanto instrumento de autoconhecimento do cursista, permite que ele desenvolva habilidades e atitudes capazes de fomentar a autonomia e, quando bem utilizada e imbuída de um feedback (retorno do professor-tutor), é capaz de despertar a atenção do aluno para seu próprio aprendizado, apontando acertos e pontos que podem ser melhorados. Entretanto, a autoavaliação por si só não é capaz de promover mudanças de atitude: é preciso que o sujeito utilize dos resultados obtidos como ponto de partida para melhorar o processo, ou seja, reflita sobre o estado em que se encontra em termos de aprendizado e aquele que deseja alcançar. 
Diante de tudo o que foi exposto, o presente estudo busca investigar a forma como se dá a avaliação na $\mathrm{EaD}$, os instrumentos empregados e sua influência na prática pedagógica de professores da Rede Estadual de Ensino do Estado do Rio de Janeiro que tenham participado de algum curso dessa modalidade nos últimos cinco anos, procurando entender em que medida a avaliação que se faz em tais cursos efetivamente contribuiu para a formação de sujeitos mais autônomos e comprometidos com a construção dos próprios saberes.

\section{AVALIAÇÃO: UM MAL NECESSÁRIO?}

A avaliação é uma prática social, um ato constante em nossas vidas. Quando transportamos o tema avaliação para educação o cenário não se mostra diferente, pois ela está presente em todos os momentos - explicita ou implicitamente. Ela incide sobre os objetivos, a metodologia e a prática docente cotidiana, o que nos alerta para a necessidade de maior compreensão de seu real significado. Segundo Luckesi (1996, p. 33), avaliar "é como um julgamento de valor sobre manifestações relevantes da realidade, tendo em vista uma tomada de decisão". Por essa concepção, não basta avaliar, mas é preciso tomar uma decisão sobre o que fazer com o objeto avaliado.

Em termos de avaliação, historicamente temos uma preponderância dos aspectos quantitativos sobre os qualitativos, desconsiderando o percurso do aluno durante 0 processo de ensino-aprendizagem. Contudo, a avaliação deve ser vista como um ato contínuo, que promova mudanças e ocorra ao longo do processo, não se esgotando nele e tampouco ao seu final. Avaliar envolve acompanhar o processo de construção do conhecimento e incentivar a capacidade autoral e inventiva do aluno em trabalhos individuais ou em grupo (PRIMO, 2006).

Segundo Perrenoud (1999), a avaliação é uma tortura medieval criada pelos colégios no século XVII para, tradicionalmente, criar hierarquias a serviço da seleção. Isso explica o sentido extremamente negativo associado ao ato de avaliar. Em contrapartida, ele também afirma que toda ação do professor contém um processo formativo, mesmo que implícito. Contudo, a avaliação formativa não se constitui uma regra entre os profissionais de educação.

A implantação de cursos EaD não é uma tarefa trivial, pois devem ser considerados uma série de fatores importantes, tais como: o custo e o benefício, a seleção dos conteúdos, as características da instituição onde o curso será implementado e, também, a forma como 
os alunos serão avaliados. A avaliação é sempre um tema espinhoso, pois classicamente serviu como instrumento meramente burocrático, como alerta Hoffmann (1991, p.196):

A avaliação nas escolas de modo geral está atrelada a função classificatória, tendo $\mathrm{o}$ aspecto quantitativo vinculado a uma prática avaliativa de observação e registro de dados, além de constituírem fenômenos com "características extremamente reprodutivistas".

Avaliar é uma importante etapa do processo de ensino-aprendizagem, constituindo um verdadeiro desafio no âmbito dos ambientes virtuais. Desafio este que compreende, principalmente, a necessidade de se fazer um sistema de avaliação que supere a simples medição do conhecimento acumulado e assuma um papel promotor de emancipação. Utilizar-se das três modalidades (diagnóstica, formativa e somativa) é um dos caminhos possíveis na EaD (AMARAL et al., 2009).

$\mathrm{Na} \mathrm{EaD} \mathrm{o} \mathrm{aluno} \mathrm{precisa} \mathrm{desenvolver} \mathrm{ainda} \mathrm{mais} \mathrm{uma} \mathrm{habilidade} \mathrm{que} \mathrm{é} \mathrm{fundamental}$ para seu sucesso: a autonomia. Através do processo avaliativo é possível analisar aspectos importantes no processo de ensino, entre eles: o desempenho de aprendizagem dos alunos; a eficiência das ferramentas educativas adotadas e a constatação (ou não) da eficácia delas, enfim, verificar se o processo educacional está ocorrendo adequadamente e os objetivos sendo alcançados.

\section{OS DESAFIOS DE SE AVALIAR NA EAD}

$\mathrm{Na} \mathrm{EaD}$ há a separação do professor e do aluno, temporal e/ou espacialmente. Durante muito tempo essa modalidade foi conhecida como a forma de educação que acontecia sem a presença do professor, com o recebimento de instruções pelos correios. Nessa forma de organização o aluno estudava sozinho (GARCIA \& CARVALHO JUNIOR, 2015). Com a inclusão das TICs, o isolamento da EaD não faz mais sentido.

O Censo da Educação Superior de 2012 apontou, em uma década, o aumento de 81\% de acesso ao Ensino Superior (FABRICIO et al., 2018), e a EaD ocupa a posição de modalidade responsável por ampliar o número de matrículas com rápida expansão dos cursos (ARRUDA \& ARRUDA, 2015). Isso se justifica pelo fato de que as instalações físicas se tornam menos relevantes na educação a distância. Os números pouco dizem sobre outros aspectos da EaD como, por exemplo, as condições dos cursos oferecidos (em termos de infraestrutura) e dos professores que fazem parte desta importante modalidade, porém, nos mostram como ela é importante para nosso país. A partir de 2015, a EaD brasileira passou a se reconhecer, mais claramente, como um sistema em crise. A 
Universidade Aberta do Brasil ${ }^{4}$ (UAB) já mostrava sinais de esgotamento desde 2013, devido à já conhecida crise econômica pela qual passa nosso país. A UAB teve seu momento de máxima expressão entre 2011 e 2013, estagnando por falta de editais (CRUZ \& LIMA, 2019). Temos que reconhecer, porém, que a EaD passou por muitas dificuldades desde que foi incluída na legislação e antes mesmo da crise propriamente dita (MILL, 2016). Isso se explica pelos fracassos de experiências anteriores, o que gerou desconfiança das pessoas. Porém, esse quadro tem se revertido, principalmente pelo envolvimento das universidades públicas.

Alguns aspectos importantes precisam de atenção quando se trata de EaD: a formação do tutor, a evasão e as ferramentas avaliativas. Segundo Custódio et al. (2019), o papel do tutor na $\mathrm{EaD}$ precisa ser repensado, inclusive no que se refere à humanização desta modalidade. De acordo com os autores, a EaD sofre com a falta de um acompanhamento pedagógico eficiente, necessitando de uma maior compreensão de como deve acontecer a tutoria e quais as características do profissional atuante. É preciso cuidar para que a interação seja preservada, superando as limitações impostas pelos recursos tecnológicos. $E$ isso é feito quando o mediador tem consciência de que a empatia, a postura e a própria linguagem podem (des)motivar o aluno.

Veloso et al. (2019) realizaram uma pesquisa bibliográfica de metadados com trabalhos publicados no Simpósio Internacional de Educação a Distância e o Encontro de Pesquisadores em Educação a Distância (SIED/EnPED), realizado no ano de 2016 na Universidade Federal de São Carlos (UFSCar). Os autores descobriram que houve uma predominância de pesquisas sobre o papel do tutor e sua interação com os alunos. O maior número de pesquisas foi proveniente das regiões Sudeste e Nordeste. A preocupação com o tutor excluiu das pesquisas o enfoque de outros partícipes do processo de construção da $\mathrm{EaD}$, como os conteudistas e os professores-formadores. A organização do trabalho docente não foi abordada em nenhum trabalho, o que é preocupante, uma vez que os aspectos pedagógicos intrínsecos à EaD fazem dela substancialmente diferente do ensino presencial.

A evasão nos cursos à distância constitui um dos grandes desafios que se apresentam à consolidação desta modalidade (GONZALEZ et al., 2016). É preciso entender os fatores que levam os alunos a desistirem para, então, implementar ações e reverter esse

\footnotetext{
${ }^{4}$ A Universidade Aberta do Brasil (UAB) foi instituída pelo Decreto 5.800, de 8 de junho de 2006, e tem como objetivo fomentar a modalidade EaD nas instituições públicas de Ensino Superior, bem como apoiar pesquisas inovadoras respaldadas por TICs.
} 
quadro preocupante. Gonzales et al. (2016), estudando 530 alunos inscritos em cursos EaD da Universidade Corporativa da Secretaria da Fazenda do Estado da Bahia, no primeiro semestre de 2014, concluíram que a localização do indivíduo influencia de forma significativa na evasão. Gênero e idade, por outro lado, não tiveram relação significativa com as taxas de abandono. Ou seja, é necessário considerar o peso do fator distância para a permanência do aluno nos cursos EaD.

Ao se pensar em avaliação na EaD, os questionamentos e angústias do ensino presencial permanecem. É preciso buscar um olhar mais amplo e sistêmico, uma prática que favoreça a construção do conhecimento, que respeite o ritmo e o tempo do aluno e que possibilite a descoberta e o desenvolvimento da autonomia, de modo a favorecer a interação e a aprendizagem colaborativa via Ambientes Virtuais de Aprendizagem ${ }^{5}$ (AVAs) - locais de interação, de colaboração e de construção coletiva do conhecimento, onde o aprendiz é responsável pela sua própria aprendizagem e pela aprendizagem dos outros membros do grupo. Os aprendizes constroem conhecimento através da reflexão, a partir da discussão em grupo. A troca ativa instiga o interesse e o pensamento crítico, possibilitando alcançar melhores resultados do que quando se estuda individualmente (FUKS et al., 2006).

A seleção dos instrumentos de avaliação a serem empregados merece uma atenção especial, pois precisam ser coerentes com a proposta de avaliação que se pretende fazer. Hoffman (2001), Luckesi (1996) e Perrenoud (1999) afirmam que o foco deve ser a estratégia didática, priorizando seu significado dentro do processo, e não o instrumento utilizado. Deve-se priorizar a sintonia com os objetivos, com a metodologia, enfim, planejar criteriosamente, de modo a favorecer a construção do conhecimento e permitir que o aluno se veja dentro do processo, tendo a oportunidade de perceber avanços alcançados e desafios não concretizados. Ele também deve ter a certeza de poder refazer o caminho da aprendizagem, e estabelecer relações entre o novo conhecimento e a sua própria realidade. De acordo com Primo (2004, p. 20):

Apesar dessas ferramentas e recursos existirem em um ambiente de EaD, os docentes ainda enfrentam muitas dificuldades, entre elas: dificuldades em avaliar aspectos qualitativos, falta de elementos que os ajudem a verificar os resultados quanto à aquisição de competências de cada aluno, ausência de parâmetros que auxiliem o docente a estabelecer estratégias adequadas para o desenvolvimento de cada aluno, resultados de desenvolvimento dos discentes não satisfatórios,

\footnotetext{
${ }^{5}$ AVAs podem ser conceituados como softwares ou sistemas de gestão que permitem distribuir conteúdo online, dotados de ferramentas que permitam a comunicação entre alunos e tutores.
} 
pois, não é levado em consideração as características individuais de cada aluno.

A avaliação deve contribuir de maneira construtiva para o processo de aprendizagem, e não apenas ser utilizada como forma de verificação de conhecimento. $A$ seleção de critérios bem elaborados e claros para todos os que estão envolvidos no processo possibilita a tomada de decisões mais consciente e menos autoritária.

Mesmo com as nítidas diferenças observadas entre a modalidade educacional presencial e a EaD, as práticas pedagógicas e métodos avaliativos empregados nesta última constituíram (e ainda constituem) meras transposições do que se fazia nos cursos presenciais, sem maiores cuidados quanto à adaptação de materiais e métodos de ensinoaprendizagem, algo extremamente necessário, uma vez que o aluno da EaD está em diferente situação em relação ao aluno do curso presencial. Quanto a este aspecto, Amaral et al. (2009) alertam para o fato de que é preciso questionar a forma de avaliação atualmente feita nos cursos à distância, representada, na maior parte das vezes, por instrumentos cristalizados e resultados classificatórios (AMARAL et al., 2009).

Neste cenário, carente de práticas avaliativas inovadoras, Sgarbet al. (2012) afirmam que o objetivo principal da avaliação, independente da modalidade considerada, é o de auxiliar professores e alunos a alcançarem o objetivo final do processo de ensinoaprendizagem, ou seja, a construção do conhecimento. Avaliar não pode, portanto, limitarse a diagnosticar um quadro de não-aprendizado, mas precisa possibilitar a tomada de decisões quanto ao que deve ser feito para reverter tal quadro. A avaliação, logicamente, deve servir ao aluno, como instrumento a favor da construção de saberes.

Bokums e Maia (2018) analisaram a visão de professores universitários a respeito da inclusão social promovida pela EaD. Dezesseis docentes de diferentes instituições participaram da pesquisa, e os autores concluíram que eles enxergam uma relação entre a EaD e a inclusão social. A maioria dos professores acredita que a EaD não é inferior ao ensino presencial e, inclusive, constitui uma importante ferramenta de integração de alunos com necessidades educacionais especiais.

Um conceito importante a ser considerado quando se trata de EaD é a questão da autonomia do educando. Peixoto e Carvalho (2010) afirmam que a educação contemporânea exige uma nova formação do sujeito, pautada na autonomia e no pensamento crítico. Em se tratando de educação a distância, promover a autonomia é essencial, pois o estudante é o principal responsável por gerir seu próprio aprendizado, mesmo que auxiliado por tutores. Portanto, é de se esperar que os cursos EaD 
desenvolvam práticas que promovam a autonomia de seus alunos, uma vez que sem ela é praticamente impossível concluir com êxito o curso.

No artigo Auto-Avaliação na Educação a Distância: uma Alternativa Viável, Primo (2008) analisa a questão da autoavaliação como uma estratégia capaz de dar novo significado à prática pedagógica que se faz na EaD. O autor detectou mudanças positivas no comportamento dos alunos de cursos de pós-graduação após realizarem uma autoavaliação com feedback do tutor. Os alunos passaram a enxergar novas possibilidades de organização do estudo individual, sugerindo pontos que precisavam ser modificados. Todos saíram ganhando, uma vez que a autoavaliação modificou não apenas os educandos, mas também as práticas pedagógicas dos tutores, fomentando a autonomia de todos. Os estudantes que não perceberam a importância de se autoavaliar foram justamente aqueles que viram a atividade com um fim em si mesma, sem atentarem para a reflexão sobre os resultados e a necessária mudança nos rumos da prática pedagógica exigida.

\section{AVALIAÇÃO DIAGNÓSTICA, FORMATIVA E SOMATIVA}

A avaliação pode ter função diagnóstica, formativa ou somativa. A avaliação diagnóstica é aquela que acontece antes do início do processo de ensino-aprendizagem, possibilitando analisar o nível de conhecimento dos alunos e, portanto, auxiliar no planejamento do professor (FREITAS et al., 2014).

A avaliação formativa é aquela que ocorre durante todo o processo educacional, permitindo, assim, observar os pontos que devem ser reparados/aperfeiçoados. Essa função da avaliação pode constituir uma importante ferramenta para alunos e tutores da EaD, por exemplo, por meio dos feedbacks fornecidos pelos tutores para as produções dos alunos. Isso pode criar condições para o discente realizar autoavaliações e modificar seus rumos no processo educacional. Os feedbacks oferecem uma interatividade constante, permitindo ao aluno se tornar mais responsável por seu próprio aprendizado (LIMA, 2012).

A avaliação somativa é aquela que ocorre ao final do processo de aprendizagem. Ela tem a finalidade de classificar o aluno, determinando assim, se ele será considerado aprovado ou reprovado, de acordo com os níveis de aproveitamento (HAYDT, 2000). Essa avaliação é a marca principal do ensino tradicional, pautado em provas e exames (LUCKESI, 1996).

$\mathrm{Na} \mathrm{EaD,} \mathrm{os} \mathrm{participantes} \mathrm{do} \mathrm{processo} \mathrm{de} \mathrm{ensino-aprendizagem} \mathrm{devem} \mathrm{explorar} \mathrm{ao}$ máximo o AVA disponível, se beneficiando da ampla interatividade proporcionada pelos 
recursos digitais. $\mathrm{E}$ isso deve acontecer em todos os momentos, inclusive os avaliativos. As práticas avaliativas podem contribuir para o desenvolvimento da autonomia dos educandos, desde que acompanhadas de uma reflexão sobre os resultados, uma vez que a avaliação como um fim em si mesma não serve ao aprendizado, cumprindo apenas a função burocrática e inadequada de classificar.

\section{MÉTODO}

O presente estudo foi realizado através de metodologia qualitativa (pesquisa descritiva bibliográfica) e uma pesquisa de campo com professores da Rede Estadual de Ensino de um município do Estado do Rio de Janeiro, se restringindo a profissionais que tenham participado de algum curso de Formação na modalidade EaD nos últimos cinco anos. O universo de pesquisa foi amplo, não se limitando a um único curso/instituição.

Foi elaborado um questionário com questões objetivas, buscando verificar os principais instrumentos avaliativos utilizados nos cursos EaD; sua influência nas práticas pedagógicas dos sujeitos-participantes; as consequências no processo de ensinoaprendizagem e o nível de percepção dos participantes sobre as diferentes funções da avaliação (diagnóstica, formativa e somativa), assim como suas contribuições para o desenvolvimento da autonomia.

O preenchimento do questionário foi de livre e espontânea vontade, sem acompanhamento dos pesquisadores durante o registro (preenchimento das respostas). Os endereços de e-mails dos docentes foram obtidos junto à direção das escolas procuradas pelos pesquisadores. Foram enviados 37 e-mails contendo os questionários anexados, solicitando devolução destes, entre os dias 06 e 20 de maio de 2019. Foram devolvidos 10 questionários preenchidos. Os dados foram tabulados e apresentados na forma de gráficos para melhor compreensão e análise.

\section{RESULTADOS E DISCUSSÃO}

Responderam à pesquisa 10 professores, os quais declararam ter participado de, pelo menos, um curso na modalidade EaD nos últimos cinco anos. A maioria dos professores tem entre 5 e 15 anos de trabalho no magistério, e apenas um deles assinalou ter mais de 15 anos de exercício.

A maioria dos professores participantes (90\%) afirma relacionar as práticas avaliativas empregadas nos cursos com suas próprias práticas pedagógicas (Figura 1). 
Embora não especifiquem o tipo de relação estabelecida (de repetição, adaptação ou substituição das práticas), infere-se que a forma como foram avaliados nos cursos os influenciou na avaliação praticada com seus próprios alunos.

Figura 1 - Gráfico representativo das respostas dos professores à questão: Pensando nas diferentes formas de avaliação durante a sua formação, você relaciona estas práticas com sua prática pedagógica atual?

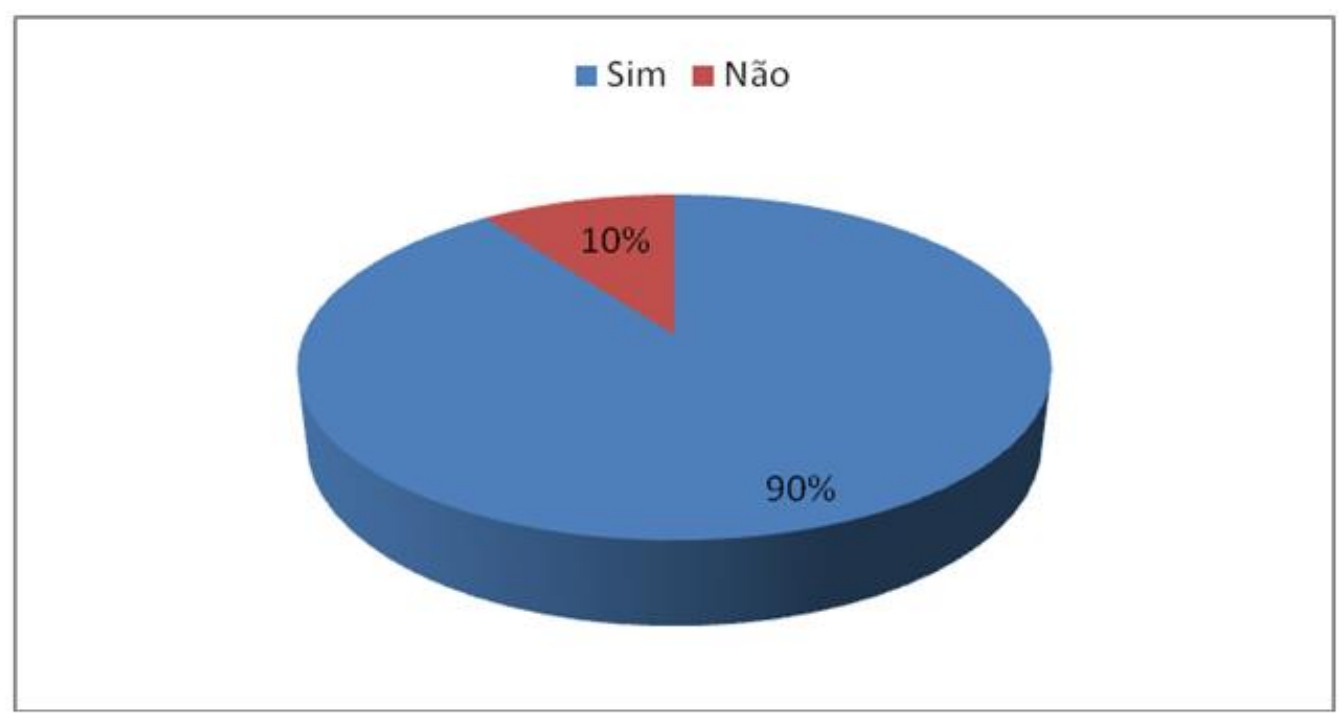

Fonte: Desenvolvido pelos próprios autores.

Quando perguntados se os critérios de avaliação interferem de forma significativa na qualidade do ensino e da aprendizagem, todos os professores responderam positivamente. Percebemos que os professores têm consciência da importância da avaliação para o processo de ensino-aprendizagem, e que os critérios utilizados interferem na qualidade final da mesma. Contudo, essa afirmação não nos dá pistas sobre o caráter da avaliação praticada. Camargo (1997), analisando os relatos sobre avaliação de 390 estudantes do último ano de cursos de Pedagogia, identificou a prevalência de aspectos negativos do processo avaliativo, acompanhada de ausência de incentivo à aprendizagem e fragilidade dos procedimentos. Entrevistando professores dos anos finais do Ensino Fundamental de duas escolas públicas de Natal-RN, Duarte (2015) concluiu que, nas escolas pesquisadas, os professores se valem de avaliações apenas para promoção dos alunos, sendo a reprovação uma espécie de castigo para o fracasso obtido nos testes. Logo, é preciso refletir sobre a concepção de avaliação dos professores. 
Em sua totalidade, os professores reconhecem a avaliação diagnóstica como um instrumento muito importante para o processo de ensino-aprendizagem. Sabemos que diagnosticar é um passo crucial para a prática pedagógica do professor, pois cria um ponto de partida para o trabalho, que não se inicia do zero, mas pode se aproveitar daquilo que 0 aluno já sabe para construir novos conhecimentos. Segundo Haydt (2000), a avaliação diagnóstica deve ser utilizada para uma tomada de decisões e, até mesmo, mudanças no planejamento do professor. Não basta diagnosticar um determinado quadro educacional, mas é preciso pensar em formas de modificá-lo. O reconhecimento dos professores quanto ao papel da avaliação diagnóstica não fornece muitas informações sobre suas decisões, porém, já representa um avanço em relação à tradicional avaliação somativa.

Curiosamente, a maioria dos sujeitos-participantes considera a avaliação quantitativa pouco importante para o processo de ensino-aprendizagem (Figura 2). Isso sugere uma inconsistência entre teoria e prática pois, via de regra, a nota obtida por meio de testes e avaliações quantitativas (um número) constitui o parâmetro para a aprovação nas disciplinas escolares (LUCKESI, 1996). Ao afirmar que a avaliação quantitativa (intimamente ligada à medida e classificação) é pouco importante diante das outras avaliações (diagnóstica e mediadora) e, contudo, continuar a depositar em notas e conceitos uma importância preponderante para a aprovação, o professor acaba por se contradizer.

Figura 2 - Gráfico representativo das respostas dos professores à questão: Como você considera a avaliação quantitativa no processo de ensino-aprendizagem?

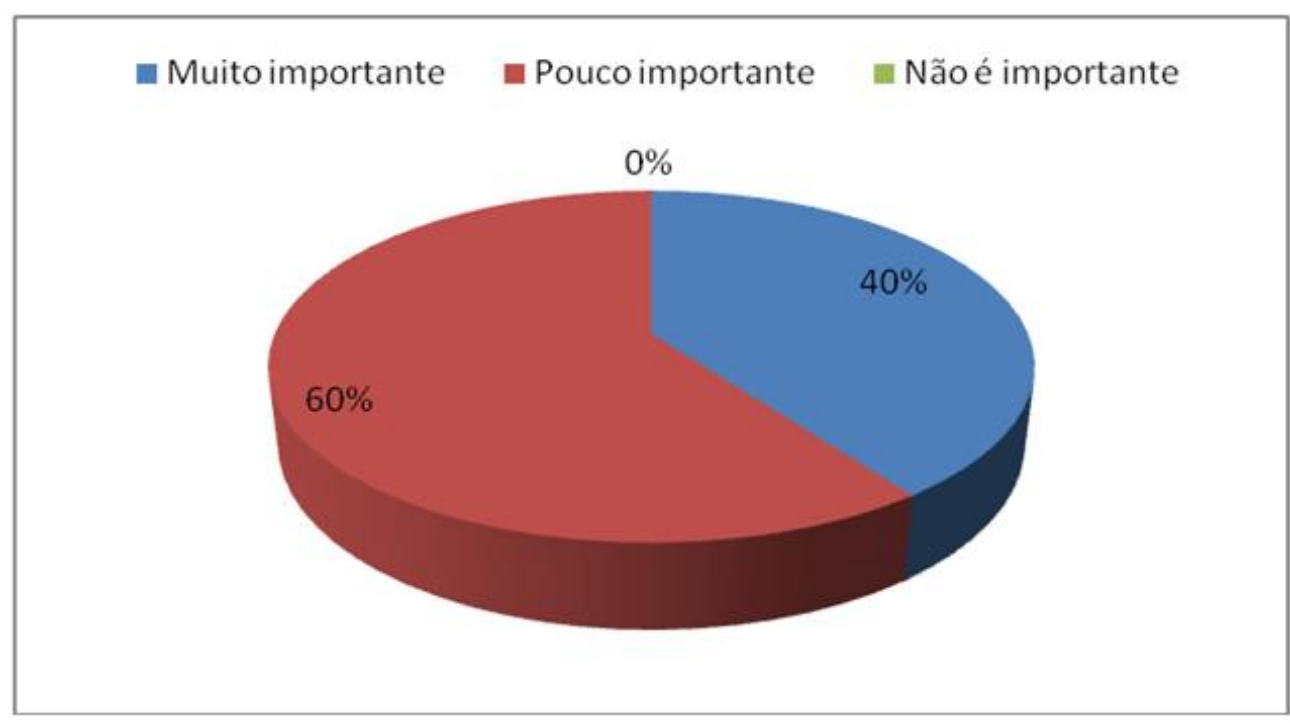

Fonte: Desenvolvido pelos próprios autores. 
Os professores, em sua totalidade, consideram a avaliação mediadora como muito importante para o aprendizado dos alunos. A avaliação mediadora, oposta à avaliação tradicional, é entendida como um processo. Contudo, esse entendimento não basta para que ela se aconteça, pois é preciso, também, estabelecer um ambiente de diálogo e reflexão (FREITAS et al., 2014). Um ambiente intimidador e organizado tal qual na educação tradicional não pode comportar novas formas de avaliação.

Percebe-se, até o presente momento, que os sujeitos-participantes possuem uma visão muito clara e consciente sobre o processo de avaliação e sua importância para o ensino-aprendizagem, ainda que algumas inconsistências surjam quando a teoria e a prática avaliativas são confrontadas. Uma explicação é que as determinações legais podem interferir na forma como o professor avalia seus alunos (o que nem sempre ocorre da maneira que ele considera mais adequada) como, por exemplo, diante da necessidade de consideraras notas obtidas de instrumentos quantitativos, quando afirma que a avaliação mediadora é a mais importante. A avaliação, nesse caso, se presta a um serviço burocrático, fugindo de seu real papel, que é o de auxiliar professores e alunos na construção do conhecimento. Segundo Bonfim et al. (2014), o histórico dos processos avaliativos no Brasil é conturbado, com objetivos variando a depender da época. Ou seja, o uso de determinados instrumentos avaliativos (como a prova oral) servia a um propósito específico, sendo substituído por outros com o passar do tempo. A partir da publicação dos Parâmetros Curriculares Nacionais ${ }^{6}$ (PCNs), a avaliação perde seu caráter de julgamento (pelo menos no que se refere às orientações oficiais, pois, em muitas escolas, ainda se destaca a avaliação tradicional).

Quando perguntados sobre os instrumentos que empregam para avaliar seus alunos, a maioria dos professores (90\%), respondeu que utiliza métodos e instrumentos diferentes daqueles empregados nos cursos EaD por eles realizados, sugerindo uma ruptura entre a forma como foram avaliados e aquela com a qual avaliam seus alunos. Percebe-se que a relação estabelecida pela maioria deles é a de substituição de instrumentos avaliativos, uma vez que não se valem dos instrumentos com os quais foram avaliados - seja por falta de suporte (no caso das formas de avaliação que exigem programas e instrumentos específicos, como o fórum, o chat e a tarefa on-line), seja por não considerarem tais instrumentos como significativos para suas práticas.

\footnotetext{
${ }^{6}$ Os PCN's são um conjunto de diretrizes contemplando as diferentes áreas de ensino e elaborados com o
} objetivo de nortear o planejamento de Secretarias de Educação e das unidades escolares. 
Em relação aos instrumentos empregados nos cursos, quanto à frequência de utilização, percebe-se que a avaliação a distância e o texto colaborativo on-line são apontados por um maior número de professores como os instrumentos avaliativos utilizados normalmente (Figura 3). Metade deles afirma que a tarefa on-line é usada com frequência. $\mathrm{O}$ chat e o questionário on-line são apontados pela maioria dos professores como instrumentos nunca utilizados nos cursos EaD por eles frequentados, assim como metade dos entrevistados afirma nunca ter utilizado o fórum de discussão.

Figura 3 - Gráfico representativo das respostas dos professores à questão: Assinale os instrumentos avaliativos empregados em seu curso e a frequência com que são aplicados.

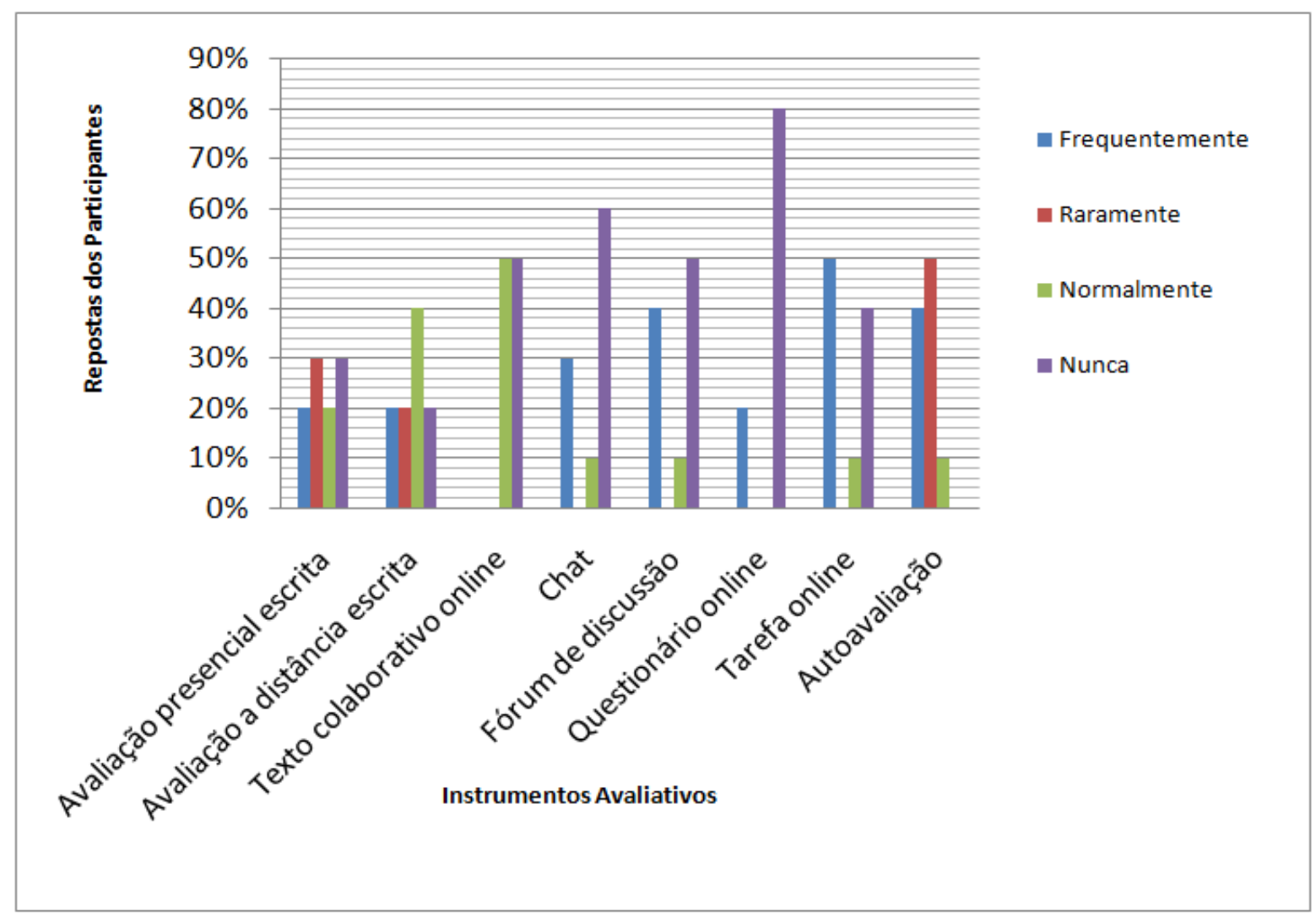

Fonte: Desenvolvido pelos próprios autores.

Metade dos professores afirma que seus cursos raramente utilizavam a autoavaliação, o que é preocupante, uma vez que esse instrumento é apontado por Primo (2008) como uma ferramenta que auxilia no desenvolvimento da autonomia e da consciência dos cursistas. Por outro lado, $40 \%$ afirmam que a autoavaliação foi empregada frequentemente em seus cursos. Tem-se, portanto, um quadro contrastante, alguns cursos 
empregam a autoavaliação como prática constante, e outros fazem dela uma atividade pouco explorada. A construção de sujeitos autônomos envolve não somente a capacidade de tomar decisões responsáveis, mas também uma reflexão sobre os rumos que as mesmas implicam. Charczuk e Menezes (2008) analisaram o potencial do registro da aprendizagem em blogs para acompanhar alunos de um curso a distância, e destacam que esse processo influenciou positivamente os alunos, por meio de autoavaliações e avaliações por pares. Ou seja, independente do instrumento utilizado, seja ele parte de um AVA ou um recurso digital externo, é possível modificar a forma como se avalia na EaD, promovendo a autonomia dos alunos.

No caso estudado por Primo (2008) a autoavaliação auxiliou os alunos de diferentes cursos de pós-graduação a perceberem a importância de participarem mais ativamente das discussões e atividades propostas. Isso só foi possível a partir do momento em que eles construíram uma visão integrada da autoavaliação, relacionando-a ao percurso de aprender, e não apenas a um momento isolado de coleta de dados sem maiores significados. A autoavaliação deve ser capaz de fazer com que o sujeito reflita sobre sua situação, buscando torná-lo mais consciente e autônomo. Autonomia está extremamente necessária para o aprendizado e permanência dos alunos nos cursos, em especial os de EaD.

Em relação à interferência dos instrumentos empregados para o aprendizado ou autonomia dos cursistas, o chat e o questionário on-line (anteriormente apontados pelos professores como os menos utilizados nos cursos) foram considerados como os instrumentos que não interferem na autonomia (Figura 4). A autoavaliação e a avaliação presencial escrita foram os instrumentos mais apontados como aqueles que interferem 0 suficiente no aprendizado e no desenvolvimento da autonomia. O fórum de discussão, a avaliação a distância e o texto colaborativo foram considerados, por uma grande parcela de professores, como instrumentos que interferem o suficiente na aprendizagem e no desenvolvimento da autonomia.

Percebe-se, mais uma vez, que a autoavaliação figura entre os instrumentos avaliativos mais apontados como possíveis de interferir/contribuir para o aprendizado e o desenvolvimento da autonomia intelectual dos professores entrevistados, assim como o chat e o questionário são apontados como aqueles que não interferem. 
Figura 4 - Gráfico representativo das respostas dos professores à questão: Como os instrumentos empregados interferiram ou contribuíram para seu aprendizado e desenvolvimento da sua autonomia intelectual?

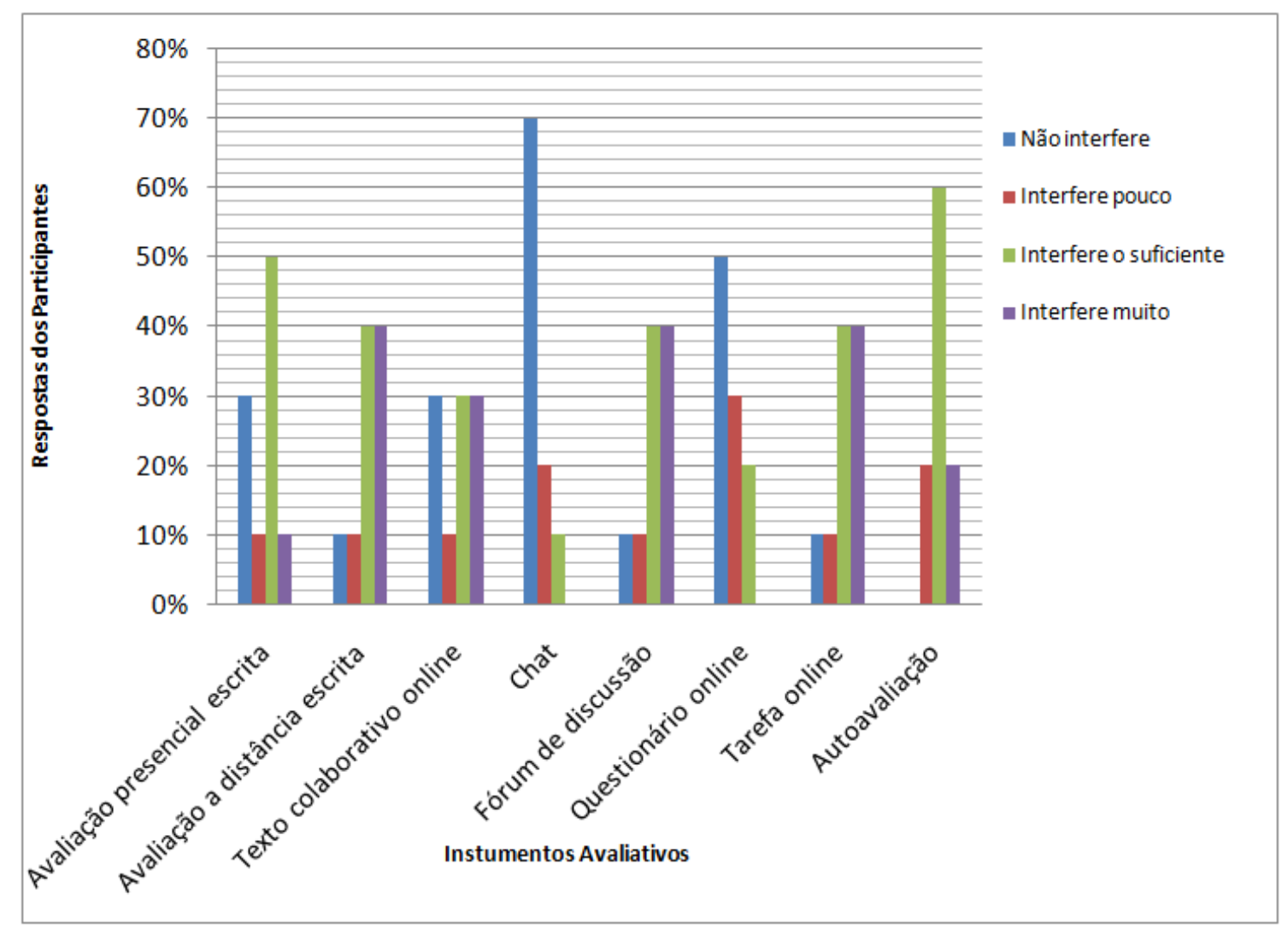

Fonte: Desenvolvido pelos próprios autores.

Quando perguntados sobre a interferência dos instrumentos pelos quais foram avaliados em suas práticas pedagógicas, a maioria dos professores (60\%) considerou que o chat não interfere nada, valor muito próximo do questionário on-line (50\%) (Figura 5). 
Figura 5 - Gráfico representativo das respostas dos professores à questão: Como você avalia a interferência dos instrumentos empregados na prática pedagógica, enquanto professor?

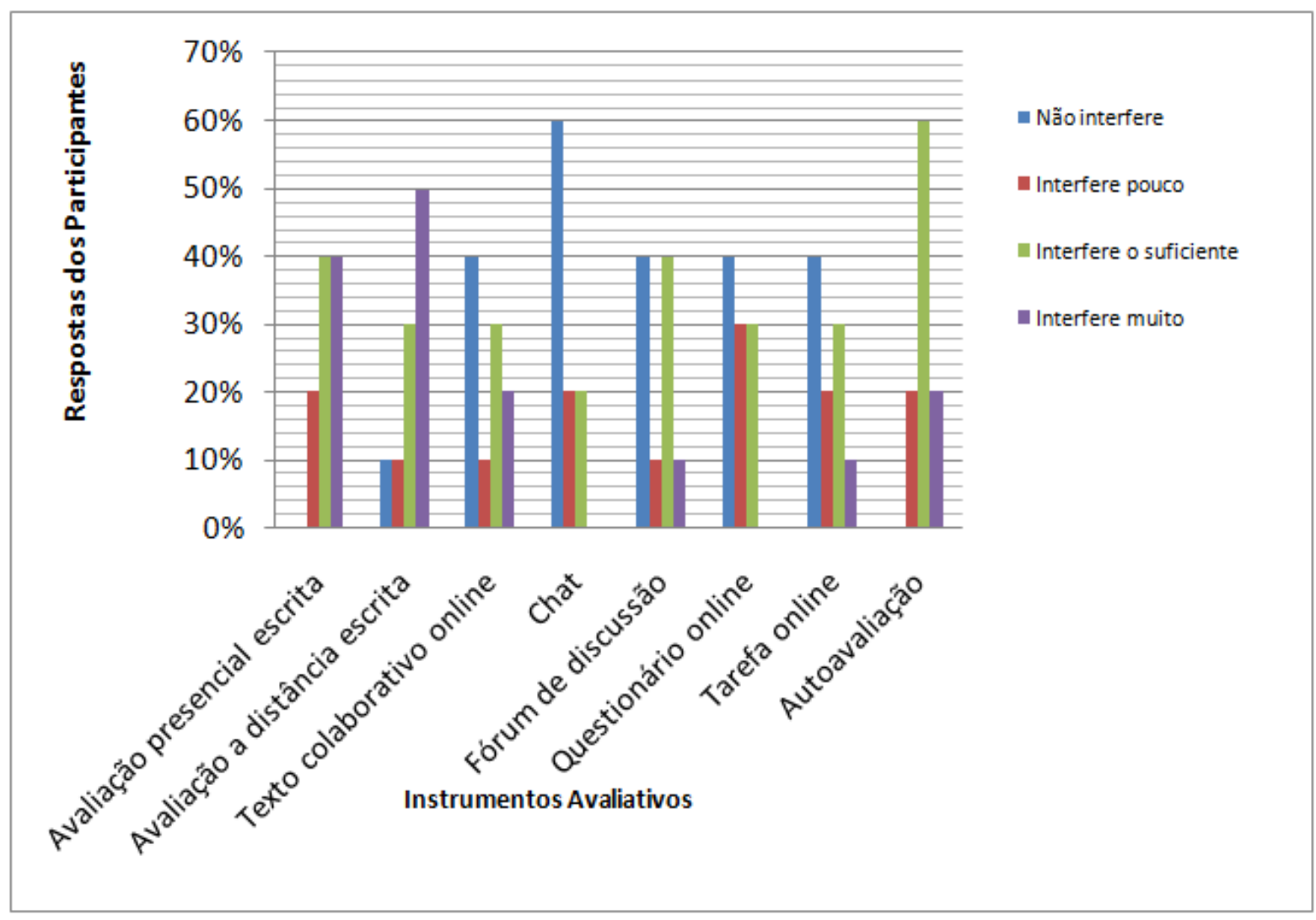

Fonte: Desenvolvido pelos próprios autores.

A avaliação presencial, a autoavaliação e o fórum foram apontados por números expressivos de professores como instrumentos que interferem suficientemente no desenvolvimento da autonomia. Embora não tenha sido perguntando quais instrumentos tais professores desejariam utilizar para avaliar seus alunos, infere-se que os professores consideram válidos para suas práticas aqueles instrumentos com os quais mais se identificam, e que apontam como importantes, como é o caso da autoavaliação, da avaliação a distância e da avaliação presencial. Curiosamente, $80 \%$ deles consideram que a autoavaliação interfere o suficiente ou interfere muito nos rumos de suas práticas pedagógicas.

Percebe-se, portanto, que os professores, em sua maioria, consideram diferentes instrumentos avaliativos como promotores de mudanças nos rumos de suas práticas pedagógicas, sugerindo que a autoavaliação (reflexão sobre o próprio percurso de aprendizado) é um instrumento muito importante, ainda que subutilizado. Após análise dos resultados, percebemos que todos os professores participantes reconhecem a importância da avaliação, tanto no que se refere à construção de conhecimentos quanto à questão do 
desenvolvimento da autonomia, enquanto cursistas e professores. Contudo, alguns instrumentos avaliativos são reconhecidos como mais importantes do que outros. A autoavaliação, instrumento potencializador da autonomia e responsável por modificações nos rumos da prática pedagógica docente, é apontada como um instrumento que interfere consideravelmente na prática pedagógica.

Não pretendemos esgotar todas as questões a respeito da avaliação em EaD neste trabalho, mas levantar questionamentos e contribuir para a expansão do tema, que pode ser aprofundado em abordagens futuras. Ao analisar os instrumentos empregados nos cursos $\mathrm{EaD}$, pretendemos entender um pouco mais a forma como os mesmos são vistos por professores e a maneira como os já referidos instrumentos interferem na prática pedagógica docente.

\section{CONSIDERAÇÕES FINAIS}

A partir dos dados obtidos por meio da revisão bibliográfica e da aplicação dos questionários, conclui-se que os professores possuem uma visão muito clara do papel da avaliação para a formação do indivíduo, ainda que uma grande parcela atribua especial destaque à avaliação quantitativa (mesmo reconhecendo a importância da avaliação formativa). Tal quadro sugere uma discordância entre o que pensam os professores sobre a avaliação e o que realmente é feito em sala de aula, uma vez que o fato de se dar maior importância para os aspectos quantitativos não altera a preponderância dos aspectos numéricos.

Os professores afirmam que foram avaliados pelos mais diversos instrumentos nos cursos EaD, sendo o chat e o questionário on-line apontados como os menos utilizados e, consequentemente, os menos importantes para o aprendizado (enquanto cursistas) e para a prática pedagógica (enquanto professores). A avaliação a distância e o texto colaborativo on-line foram apontados como os mais utilizados nos cursos EaD, ao passo que a autoavaliação e a avaliação presencial escrita foram apontadas como os de maior significado para a prática docente.

Percebe-se que os professores tendem a utilizar em suas práticas avaliativas os instrumentos que julgaram importantes para sua formação, e com os quais mais se identificaram. Tais professores, contudo, não se limitam simplesmente a reproduzir em suas práticas a avaliação à qual foram submetidos, mas buscam, em sua maioria, avaliar de forma diferenciada. 
Verificou-se que a autoavaliação é um instrumento de importância reconhecida pelos professores, cuja empregabilidade cria um paradoxo: ora ela é pouco empregada, ora simplesmente não é utilizada nos cursos EaD. Enquanto instrumento promotor de autonomia e reflexão, a subutilização da autoavaliação é preocupante, especialmente quando pensamos que ela é capaz de influenciar positivamente a formação do indivíduo, colocando-o no ponto-chave da gestão de seu aprendizado e possibilitando que ele reflita sobre onde está e onde deseja chegar.

Constata-se a necessidade de novas pesquisas a respeito da avaliação que se faz atualmente na $\mathrm{EaD}$ e, consequentemente, dos instrumentos utilizados, como forma de melhor compreender sua influência sob esta crescente modalidade educacional. Não é possível continuar com a simples reprodução das práticas empregadas no ensino presencial, pois as necessidades e exigências desta modalidade trazem inúmeros desafios educacionais e, em específico, avaliativos.

\section{REFERÊNCIAS}

AMARAL, M.A.; ASSIS, K.K.; BARROS, G.C. Avaliação na EaD: contextualizando uma experiência do uso de instrumentos com vistas à aprendizagem. In: Educere - IX Congresso Nacional de Educação, Pará, PUCPR, 2009.

ARRUDA, E. P.; ARRUDA, D.E. P. (2015). Educação a distância no Brasil: políticas públicas e democratização do acesso ao Ensino Superior. Educação em Revista, Belo Horizonte, 31(3), p.321-338.

BOKUMS, R. M.; MAIA, J. F. (2018). Educação a Distância (EaD) no Brasil: uma reflexão a respeito da inclusão social. Diálogo, Canoas, 1(38), p.99-111.

BONFIM, E.A.; TIAGO, G.M.; BARONI, M.P.M.A. Avaliação da aprendizagem no Brasil: os documentos oficiais e a prática cotidiana na sala de aula. In: Concistec - Congresso Científico da Semana Tecnológica, São Paulo, IFSP, 2014.

CAMARGO, A.L.C. (1997). O discurso sobre a avaliação escolar do ponto de vista do aluno. Rev. Fac. Educ., São Paulo, 23(1-2), p. 1-15.

CHARCZUK, S.B.; MENEZES, C.S. Avaliação em EaD: a experiência realizada no curso de Pedagogia a distância (PEAD/UFRGS). (2008). Novas Tecnologias na Educação, Rio Grande do Sul, 6(1), 1-8.

CRUZ, J. R.; LIMA, D. C. B. P. (2019). Trajetória da educação a distância no Brasil: políticas, programas e ações nos últimos 40 anos. Jornal de Políticas Educacionais, Goiás, 13, p.1-19. 
CUSTÓDIO, S. G.; PACHECO, M. M. D. R.; MARINELO, C. A. S. R.; COSTA, L. R. S.; SANTOS, G. V. dos. (2019). O Papel do Tutor na Humanização da Aprendizagem na Educação a Distância. Ead em Foco, Rio de Janeiro, 9(1), p.1-12.

DUARTE, C.E.L. Avaliação da aprendizagem escolar: como os professores estão praticando a avaliação na escola. Holos, Rio Grande do Norte, 8(31), 53-67.

FABRICIO, L. B.; SANTOS, S. L. dos; SANTO, J. A. do E.; MOREIRA, L. R. O Ensino de História na Educação à Distância (EaD): novos caminhos para a aprendizagem online. (2018). Holos, Rio Grande do Norte, 2, p.307-317.

FREITAS, S.L.; COSTA, M.G.N.; MIRANDA, F.A. (2014). Avaliação educacional: formas de uso na prática pedagógica. Meta: Avaliação, Rio de Janeiro, 6(16), 85-98.

FUKS, H.; PIMENTEL, M.G.; GEROSA, M.A.; FERNANDES, M.C.P; LUCENA, C.J.P. (2006). Novas estratégias de Avaliação Online: aplicações e implicações em curso totalmente a distância através do ambiente AulaNet (pp. 369-385). In Santos, E.; Silva, M. (org). Avaliação da Aprendizagem em Educação Online. São Paulo: Loyola.

GARCIA, V. L.; CARVALHO JUNIOR, P. M. Educação a distância (EAD), conceitos e reflexões. (2015). Medicina Ribeirao Preto. Online, Ribeirão Preto, 48(3), p.209-213.

GONZALEZ, R. A.; NASCIMENTO, J. G. do; LEITE, L. B. (2016). Evasão em cursos à distância: um estudo aplicado na Universidade Corporativa da Secretaria da Fazenda do Estado da Bahia. Rev. Serv. Público, Brasília, 67 (4), p.627-647.

HAYDT, R. C. Avaliação do processo Ensino-Aprendizagem. São Paulo: Ática, 2000.

HOFFMANN, J. Avaliação: Mito e Desafio: uma perspectiva construtivista. Porto Alegre: Mediação, 1991.

LIMA, C. C. de. Avaliação formativa na EaD: o curso de capacitação para formação de tutores. In: Sied - Simpósio Internacional de Educação A Distância, São Carlos, UFSCAR, 2012.

MILL, D. (2016). Educação a Distância: cenários, dilemas e perspectivas. Revista da Educação Pública, Cuiabá, 2(59), p.432-454.

LUCKESI, C. C. Avaliação da aprendizagem escolar. São Paulo: Cortez, 1996.

PEIXOTO, J.; CARVALHO, R. M. A. de. (2010). A noção moderna de autonomia e o papel do aluno na educação a distância. Educativa, Goiânia, 13(2), p.275-284.

PERRENOUD, P. Avaliação: da excelência à regulação das aprendizagens - entre duas lógicas.Porto Alegre: Artes Médicas Sul, 1999.

PRIMO, A. (2006). Avaliação em processo de educação problematizadora online (pp. 3849. In Silva, M.; Santos, E. (orgs.). Avaliação da Aprendizagem em educação online. São Paulo: Loyola. 
PRIMO, L. Auto-Avaliação na Educação a Distância uma alternativa viável. In: Congresso Da Sociedade Brasileira De Computação, Belém do Pará, SBC, 2008.

PRIMO, L. P. C. Metodologia para acompanhamento de cursos de EaD e avaliação de competências - A2 COMP. 2004. Dissertação (Mestrado em Informática Aplicada) Universidade de Fortaleza: Fortaleza - CE.

VELOSO, B. G.; MILL, D.; MONTEIRO, M. I. Docência, educação a distância e tecnologias digitais: um estudo bibliométrico. (2019). Revista Eletrônica de Educação, São Carlos, 13(1), p.319-335.

Artigo recebido em: 05 de junho de 2020. Aceito para publicação em: 22 de julho de 2020.

Manuscript received on: June 05, 2020

Accepted for publication on: July 22, 2020 